\title{
Standard care interventions applied during heel prick in the neonatal unit
}

\author{
G. De Clifford-Faugère ${ }^{1,2}, \mathrm{M}$. Aita ${ }^{1,2,3}$
}

${ }^{1}$ Université de Montréal, Faculty of Nursing, Montreal, Canada; ${ }^{2}$ Research center CHU Sainte-Justine; ${ }^{3}$ Quebec Network of Nursing Intervention Research [RRISIQ]

\section{Background}

\section{- Preterm neonate can feel pain and expresses it through specific signs ${ }^{1}$.}

- The number of heel prick has declined over the last decade but remains high at almost one a day $^{2}$.

- Repeated and untreated pain has consequences for the preterm neonate such as hypersensitivity to pain ${ }^{3}$, as well as important repercussions on their motor and intellectual developments ${ }^{4}$.

- The use of non pharmacological interventions for pain management is desired to prevent these consequences $5,6,7$.

\section{Objective}

Report findings concerning nurses' pain management interventions realized in a NICU during heel prick.

\section{Methods}

Design. Pilot study.

Setting. Neonatal Intensive Care Unit (NICU) level III.

Participants. A convenience sample of 20 nurses.

Inclusion criteria. 1) at least 6 months of experience, 2) speak and write french.

\section{Procedure.}

- self-administered questionnaires

- among these 20 nurses, 11 did a heel prick on preterm infants for the pilot study (questions were added to the questionnaire)

- these 12 nurses were observed during heel prick in order to evaluate which and how pain management interventions were done

Statistical analysis. Descriptive

\section{Results}

Care considered standard by nurses in theory

For $95 \%$ of nurses, sucrose is a systematic pain management intervention, but it is not associated with non-nutritive sucking $(15 \%)$, contrary to the recommendations 5,7 .

Pain management interventions involving parents such as breastfeeding and skin-to-skin contact are infrequently done (blood samples at 6 o'clock AM in their NICU).

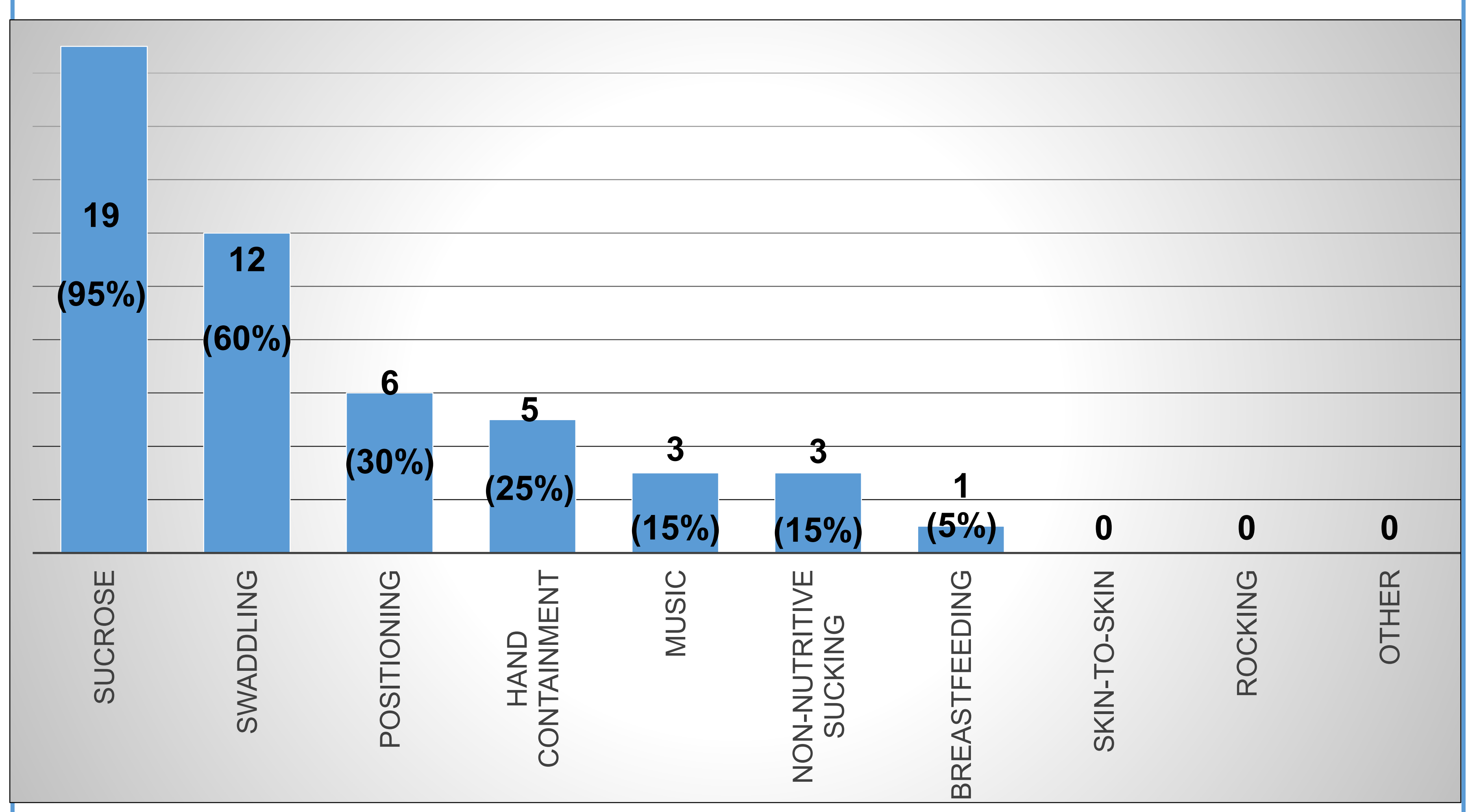

Differences between questionnaires and observations

Differences between the care that nurses claim to perform systematically for pain and those really observed in practice:

- Positioning, which initially appeared not to be an intervention performed for pain in the NICU was used as often as sucrose, i.e for 7 of the 11 preterm infants.

- Observed with 2 infants, swaddling technique was not properly performed in order to be effective.

- $36 \%$ of the nurses did not administered sucrose during heel prick, and $91 \%$ answered that they administered sucrose with a pacifier, whereas it was only done in $27 \%$ of the cases. 8 nurses reported having administered sucrose, but only 7 actually did it (social desirability ${ }^{8}$ ).

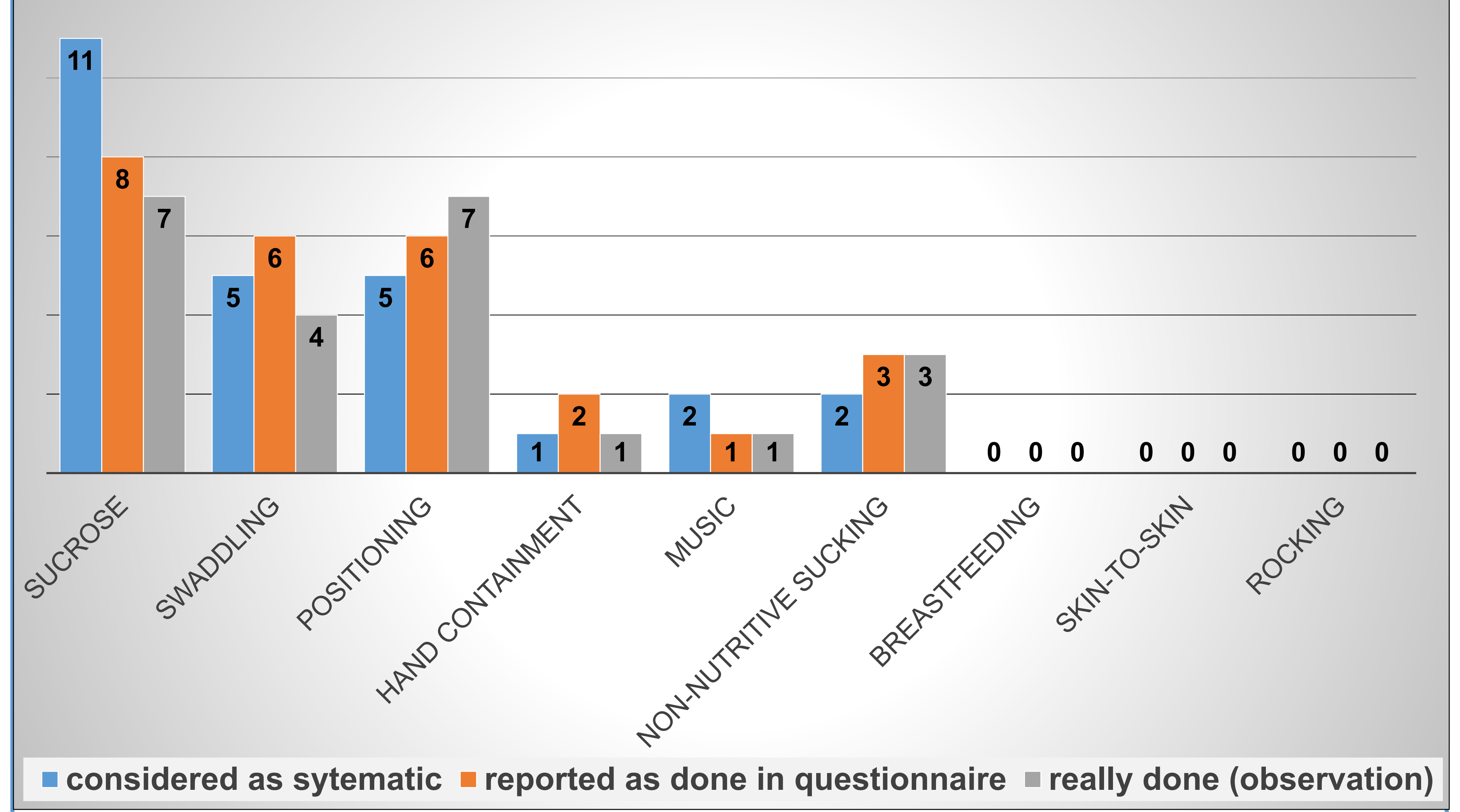

Infants received one $(n=2)$ or several interventions $(n=9)$

Heterogeneity: 1) sucrose is a standard intervention for $95 \%$ of nurses but does not always appear to be administered for pain $(64 \%), 2)$ positioning is more apply $(64 \%)$ than reported in the questionnaire (45\%), 3) swaddling was reported as a systematic intervention by $45 \%$ of nurses but does not appear to be adequately applied (36\%).

\section{Conclusion}

In view of the application of pain management interventions by nurses in their practice, it would be essential to revise standard care applied during painful procedures, particularly for a research context.

This step would ensure that the conditions are similar between the experimental group and the control group, allowing an appropriate comparison between the study groups.

\section{References}

Anand, K. J. et Hickey, P. R. (1987). Pain and its effects in the human neonate and fetus. The New England journal of medicine, 317(21), 1321.

Johnston, C., Barrington, K. J., Taddio, A., Carbajal, R. et Filion, F. (2011). Pain in Canadian NICUs: Have We Improved Over the Past 12 Years? The Clinical Journal of Pain, 27(3), 225

Valeri, B. O., Ranger, M., Chau, C. M., Cepeda, I. L., Synnes, A, Lin Bures Predict Pain Intensity at School Age in Children Porn Very Preterm. Clinical Journal of Pain.

Thomas, J Synnes, A R., Cepeda, I. L., Keidar, A., . . Johannesen, D. (2009). Neonatal pain, parenting stress and interaction, in relation to cognitive and motor development at 8 and 18 months in preterm infants. Pain, 143(1-2), 138-146.

. Prention and Management Pillai Riddell R. R Racine N. M Gennis, H. G Turcotte K Uman, L. S., Horton, R. E., . . Lisi, D. M. (2015). Nonpharmacological management of infant and young child procedural pain. Cochrane Database of Systematic Review, 12. Stevens, B., Yamada, J., Ohlsson, A., Haliburton, S. et Shorkey, A. (2016). Sucrose for analgesia in newborn infants undergoing painful procedures. Cochrane Database of Systematic Reviews (7)

, C. T. (2012). Nursing research: Generating Philadelphia: Lippincott Williams \& Wilkins.

\section{Centre de recherche} C) CHU Sainte-Justine

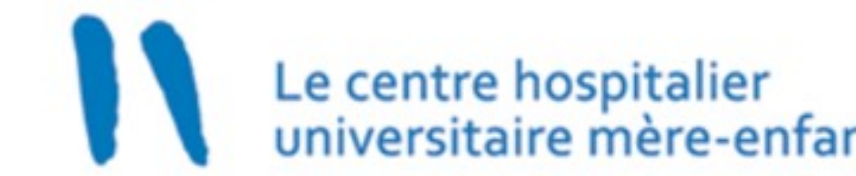

\section{Université đh $\overbrace{\substack{\text { Network } \\ \text { Réseau }}}^{R}$}

\section{Contact}

gwenaelle.de.clifford@umontreal.ca
